\title{
Mercury-Free Gold Extraction Using Borax for Small-Scale Gold Miners
}

\author{
Peter Wiltje Uitterdijk Appel1 ${ }^{1}$, Leoncio Degay Na-Oy² \\ ${ }^{1}$ Geological Survey of Denmark and Greenland, Denmark \\ ${ }^{2}$ Emerald Mountain Philippines, Denmark \\ Email: pa@geus.dk
}

Received 6 March 2014; revised 5 April 2014; accepted 1 May 2014

Copyright (C) 2014 by authors and Scientific Research Publishing Inc.

This work is licensed under the Creative Commons Attribution International License (CC BY).

http://creativecommons.org/licenses/by/4.0/

(c) (i) Open Access

\begin{abstract}
Small-scale gold mining is the largest anthropogenic contributor of mercury pollution on planet Earth. The miners grind gold ore together with mercury in order to recover the fine gold grains. The gold amalgam is burned whereby the mercury evaporates and gold is left behind. This processing extracts only a fraction of the gold in the ore and the released mercury causes serious global health and environmental problems. However, a mercury-free method described below has proved to extract up to twice as much gold without need of investment in new processing equipment and without longer processing time. The method has successfully been tested in the Philippines, Indonesia, Tanzania, Bolivia and Zimbabwe.
\end{abstract}

\section{Keywords}

\section{Small-Scale Mining, Amalgamation, Borax, Gold, Pollution, Mercury Flour}

\section{Introduction}

Small-scale gold mining has been carried out by millions of miners for centuries and has provided food on the table for the miners and their families. It is carried out with very primitive means such as hammer and chisel. It is widespread in Southeast Asia, Africa, Middle and South America and the number of miners is rapidly increasing. The commonly used way to extract gold by the miners is amalgamation, where the ability of mercury to amalgamate with gold is used to capture fine gold particles, whether from hard rock deposits or placer deposits. The method does not require investment in expensive equipment. Although mercury trade has been forbidden for decades in most countries, a flourishing black market has ensured, and still ensures, abundant supply of mercury for the miners. In spite of the newly signed Minamata convention, small-scale gold mining activities will continue to release mercury into the environment unless attractive replacement of mercury is promoted. 
For centuries, coal burning has been the major source of anthropogenic mercury pollution of planet Earth. Recently, however, that leading role has been surpassed by small-scale gold mining. The most recent estimate of mercury release from small-sale gold mining is an annual release of 1690 tons mercury to the atmosphere, which is approximately twice as much as coal burning releases [1].

About thirty years ago, a mercury-free gold extraction method was invented in the Philippines. In this process, a heavy mineral concentrate is produced by gravitation. Then borax is added to the heavy mineral concentrate. This reduces the melting point of gold and other heavy minerals, enabling gold to be melted out of the ore with inexpensive equipment. The method was gradually adopted by around 20,000 small-scale miners. Unfortunately it did not spread to other parts of the Philippines or other countries. The present paper describes that the mercury-free method is environmentally benign and with the bonus that the miners recover up to twice as much gold without investment in expensive equipment.

\section{Whole ore Amalgamation}

One of the most widespread gold extraction methods used by small-scale gold miners is whole ore amalgamation. In brief the method is as follows.

After gold ore is mined, it is crushed to about walnut size mostly by hand. The crushed material is transferred to a metal drum and milled with hard metal rods or balls together with water and mercury. The amount of mercury added to the milling depends on type of ore, expected amount of gold and size of drum. It ranges from a few grams up to kilograms. The drum rotates for several hours. Milling time depends on hardness of gold ore, and can require up to 24 hours. During milling mercury "capture" gold particles by forming a gold amalgam. The milled material is drained into a tub and mercury is recovered. The amalgam is heated whereby mercury evaporates and gold is left behind. The recovered gold contains five to ten percent mercury, which will be burned off by gold dealers.

Burning off mercury from the amalgam impose serious health hazards since inhaled mercury vapour passes into the blood system and causes permanent damage to the central nervous system. If inhaled by a pregnant woman her foetus will have an increased risk of being born mentally and/or physically disabled.

\section{Formation of Mercury Flour}

Further disadvantages to the mercury method are related to the formation of mercury flour. During milling the constant pounding of mercury by hard metal rods or balls cause much of the mercury to form mercury flour. Mercury flour comprises small droplets of mercury, less than a millimetre in size; the droplets are unable to coalesce. Mercury flour is evenly distributed in the milled gold ore (Figure 1), and cannot be captured by the miners and, therefore will end in the tailings.

Sampling of tailings in and around small-scale mining sites on the island of Sumbawa, Indonesia and Philippines showed alarming high concentrations of mercury in tailings, as well as very high gold contents (Table 1).

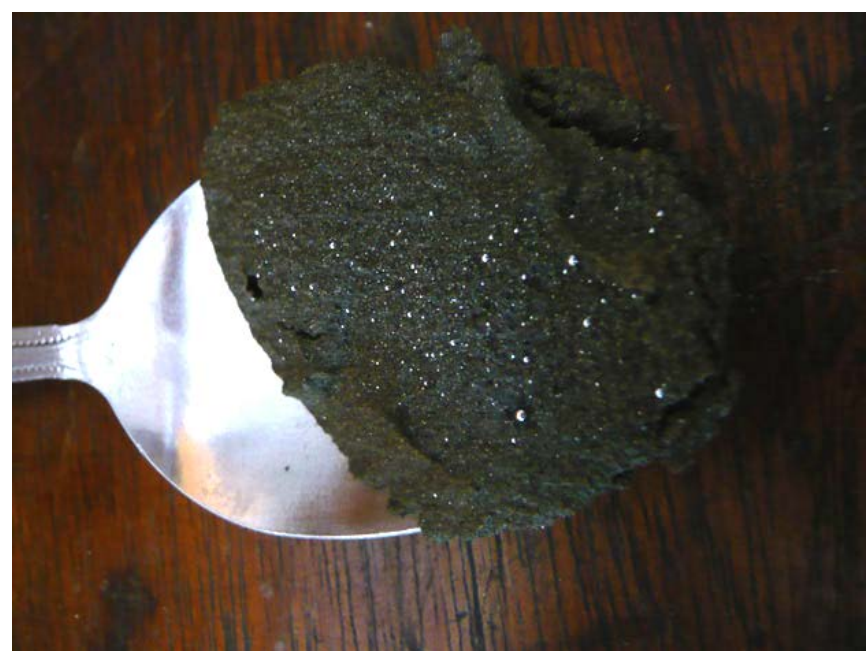

Figure 1. A spoonful of milled gold ore littered with mercury flour. 
Table 1. Gold and mercury contents in tailings from Indonesia and the Philippines.

\begin{tabular}{lccc}
\hline Country & Sample & Hg & Au \\
\hline & No & ppm & ppm \\
Indonesia & 540,119 & 2010 & 9.54 \\
Indonesia & 540,120 & 100 & 3.92 \\
Philippines & 494,855 & 250 & 16.5 \\
Philippines & 494,856 & 200 & 13.6 \\
Philippines & 494,857 & 120 & 14 \\
Philippines & 494,858 & 73 & 13.1 \\
Philippines & 494,859 & 110 & 1.23 \\
\hline
\end{tabular}

The major gold loss is not only a problem for the miners, but also for the country in decreased contribution to the GNP. A loose estimate indicates that in the order of 5 to 10 tons of gold is lost in tailings in the Philippines annually out of an annual production of 41 tons [2].

Mercury flour has another very unfortunate capacity; it often floats on water (Figure 2). Floating mercury flour can be transported for long distances through the drainage system with severe health and environmental consequences. Formation of mercury flour also results in economic disadvantages for the small-scale miners. During milling mercury captures gold. Mercury flour thus contains large amounts of gold which is lost to the environment.

In order to evaluate the economic implications of formation of floating mercury flour, five samples of floating mercury flour were collected in the Philippines January 2014. Floating mercury flour was scooped out of water running from the milling sites. The flour was scooped into a small funnel lined with filter paper. The water was drained and the filter paper was placed in a sealed plastic bag. The samples were analyzed by Actlabs Canada for mercury, silver and gold (Table 2). The results demonstrate how serious whole ore amalgamation is in causing major loss of gold. For every $7 \mathrm{~kg}$ mercury released through floating mercury flour $1 \mathrm{~kg}$ of gold is lost (Sample B2). In Sample Cam $1202 \mathrm{~kg}$ of floating mercury flour will carry away $1 \mathrm{~kg}$ of gold to the environment.

\section{Mercury-Free Gold Extraction Using Borax}

More than thirty years ago a group of small-scale gold miners in Benguet province North Philippines discovered a mercury-free gold extraction method, and during the following years around 20,000 miners in that area adopted the new process.

The method, which is based on gravitational concentration of heavy minerals, works as follows. The mined gold ore is crushed and milled in drums with hard metal rods or balls. The milled material is drained into a sluice and further washed down a chute covered with felt. The heavy minerals including gold are captured by the felt. When the felt is loaded it is rinsed by washing in a tub and subsequently a gold concentrate is produced by panning. The gold concentrate is placed in a small piece of plastic together with equal amounts of borax and a few drops of water and then placed in a clay bowl. Heating with a gasoline burner or acetylene flame causes all the heavy minerals to melt and the molten gold will collect in the bottom of the bowl (Figure 3), from where a gold pellet can be picked up by the tip of a knife. Gold has a melting point of $1063^{\circ} \mathrm{C}$. By adding borax the melting point decreases for gold and the other heavy minerals. The process is described in an educational video [3].

This method has several advantages compared to whole ore amalgamation. The main advantage is that it is mercury-free and thus environmentally benign. Further advantages to other mercury-free methods is that it does not require investment in expensive equipment, it is easy to learn for small-scale miners, and it takes approximately the same time as whole ore amalgamation. In addition, the method comes with economic benefits to the small-scale miner, since gold is not lost to the environment in mercury flour.

The mercury-free gold extraction using borax has successfully been tested on a variety of gold ores in Philippines, Indonesia, Tanzania and Bolivia. Recently a successful gold extraction using the method in Zimbabwe was carried out (Stephen Boese-O’Reily personal communication). In the Philippines a Danish-funded two year 


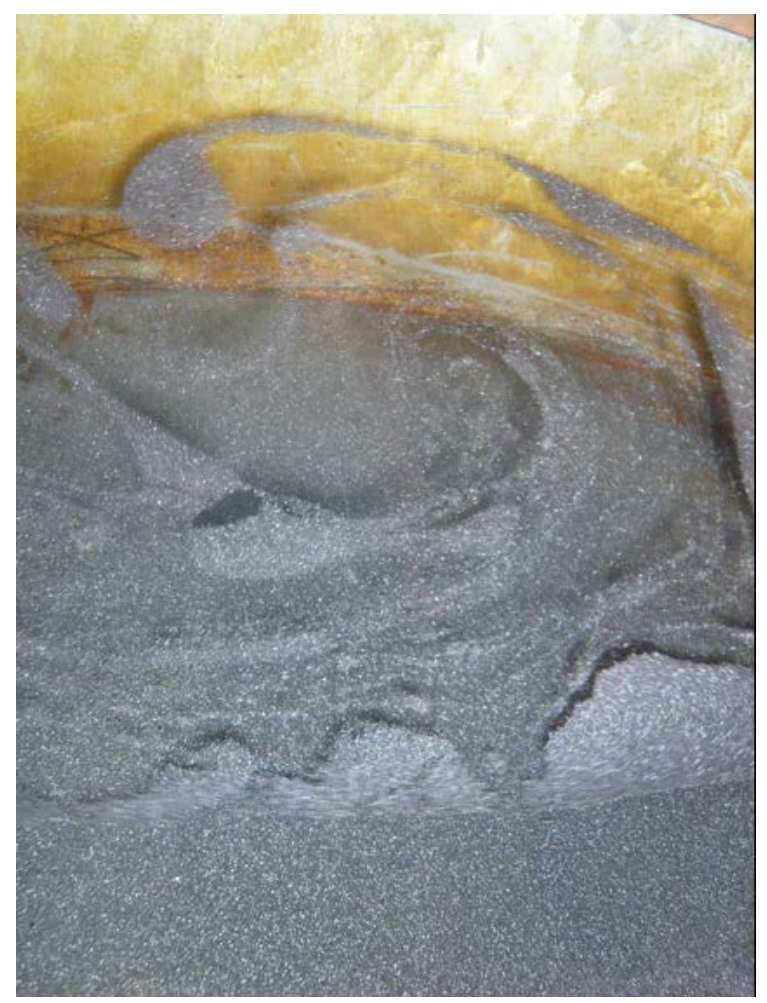

Figure 2. Thick layer of mercury flour floating on water in a pan.

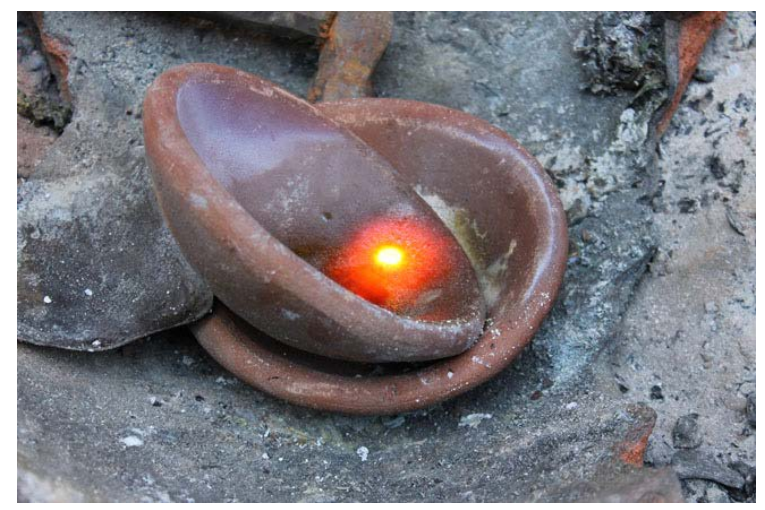

Figure 3. Gold has been smelted out of a heavy mineral concentrate and is ready to be picked out.

Table 2. Hg, Ag and Au contents in floating mercury flour. Sample areas Benguet (B) and Camarines del Norte (Cam). Dry weight of filters $\sim 0.4$ gram.

\begin{tabular}{ccccc}
\hline & Hg & Ag & Au & Hg/Au \\
\hline ug/filter & ug/filter & ug/filter & 653 \\
B 1 & 74,400 & 55.5 & 114 & 7 \\
B 3 & 377 & 87.8 & 54 & 1202 \\
B 4 & 149,000 & 78.8 & 124 & 204 \\
Cam & 69,900 & 90.5 & 342 & 1314 \\
\hline
\end{tabular}


teaching and training project has been carried out during which more than 1800 small-scale gold miners have replaced mercury with borax in their gold extraction [4]. The described method has worked on most of the gold ores tested apart from the Mt Muro ores in central Kalimantan. In the Mt. Muro ore gold is enclosed in argentite. Therefore we could not obtain a gold concentrate. Amalgamation works fine on the Mt Muro ore. Gold is often enclosed in iron sulphides. If that gold shall be extracted either using amalgamation or borax the ore has to be roasted. Without visible gold the mercury-free gold extraction method using borax does not work properly.

In Indonesia a GAHP (Global Alliance on Health and Pollution) financed project has successfully demonstrated the method on the islands of Sumbawa and Sulawesi. In Tanzania a project financed by Geocenter Denmark carried out successful demonstrations in the Mbeya region. In Bolivia a project financed by EU, Danish Embassy on La Paz and Blacksmith N.Y. made convincing demonstration of the method.

\section{Comparison between Mercury-Free and Amalgamation Extraction Methods}

It seems obvious that small-scale gold miners want to replace amalgamation with mercury-free gold extraction methods; especially considering the fact that it causes no health or environmental problems and that they recover more gold. It is unfortunately not always easy to convince miners to change working methods. Many claim that they have used mercury for more than thirty years and do not want to change working habits. Furthermore they do not believe that they will recover more gold by changing extraction methods.

We have there for carried out a number of demonstrations where we extract gold from gold ores using borax and amalgamation and compare the gold recovery and the time spent on recovering gold. The demonstrations were set up like a contest and the amalgamation method was each time carried out by experienced local smallscale gold miners.

In Le Suerte gold mine in Northwest Bolivia two tests were made in the autumn 2013. In each test around 50 kilograms of milled ore were carefully split. The ore used for the test is a shear zone with quartz containing pyrite, arsenopyrite and visible gold. One batch was mixed thoroughly with mercury and the extracted amalgam was burned and the gold weighed. The other batch was treated mercury-free and gold smelted with borax. In both cases the mercury-free gold extraction recovered most gold. The results are shown in Table 3 . The time involved processing gold by the two methods was measured. The mercury-free method was almost 10 percent faster than amalgamation.

In Gaang, North Philippines, three comparative tests were carried out in order to demonstrate whether gold extraction using amalgamation or borax gave the highest yield ${ }^{4}$. The gold ore used for testing is a breccia with quartz and pyrite with visible gold. Two sets of tests were performed, one using mercury and the other using gravitation followed by borax smelting. Since gold is not evenly distributed in gold ore, seven sacks of ore were used for each of the tests. Results from each set of tests are shown in Table 3. After the teachers [4] left, the miners decided to carry out the experiments again but on their own. They milled 14 sacks of gold ore for a short time. Then they split the crudely milled ore in two equal lots. One lot was re-milled with mercury and the other re-milled in a clean drum. 7.2 grams of gold was extracted using mercury and 22.3 grams of gold was recovered using gravitation followed by borax smelting (Gang 4, Table 3).

In Kias, Benguet province, Northern Philippines two runs were carried out in January 2014. In each run eight sacks ( $300 \mathrm{~kg}$ ) of gold ore were milled for two hours. The milled material was carefully separated in two parts. One half was milled for two hours with mercury and the other half was processed mercury-free and gold smelted with borax. In both experiments the mercury-free method yielded most gold. The results are shown in Table 3 and Figure 4. Time spent on the two methods was measured and the mercury-free method was 30 percent faster than the amalgamation process.

Gold pellets on the left are from amalgamation, at the right from borax smelting

The reason that mercury-free gold extraction gives higher gold recovery is that no mercury flour is formed during milling of the gold ore.

\section{Toxicity}

The toxicity of mercury has been known for hundreds of years, and was globally recognized especially after the Minamata disaster, which took place in Japan some sixty years ago. It has recently been questioned whether borax is toxic to mankind especially reducing the fertility of men. Recent research on the claimed toxicity of borax has shown that borax has none or negligible health impacts [5]-[8]. 


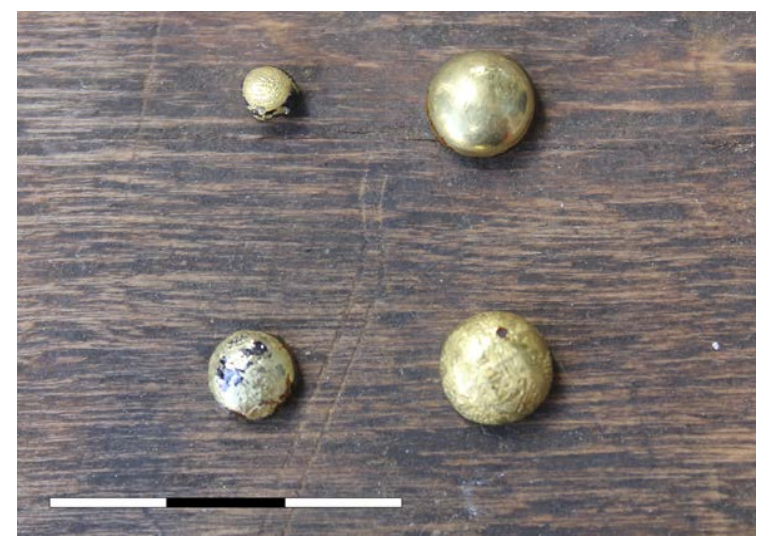

Figure 4. Result of the competition in Kias. Scale $3 \mathrm{~cm}$.

Table 3. Gold recovery using amalgamation vs. borax smelting.

\begin{tabular}{ccc}
\hline Location & Amalgamation & Borax smelting \\
\hline Suerte 1, Bolivia & 0.1 gram & 0.5 gram \\
Suerte 2. Bolivia & 0.4 gram & 0.5 gram \\
Gaang 1. Philippines & 1.2 gram & 3.2 gram \\
Gaang 2. Philippines & 2.3 gram & 4.8 gram \\
Gaang 3. Philippines & 1.8 gram & 4.2 gram \\
Gaang 4. Philippines & 7.2 gram & 22.5 gram \\
Kias. Philippines 1 & 0.4 gram & 1.1 gram \\
Kias. Philippines 2 & 0.8 gram & 1.3 gram \\
\hline
\end{tabular}

\section{Conclusions}

The above results show that mercury-free gravitational gold extraction using borax smelting recovers significantly more gold than using amalgamation. The experiments reported above show that mercury-free process being a little faster than whole ore amalgamation.

A major advantage with the mercury-free process is that the same equipment can be used in the whole ore amalgamation after careful cleaning of the mercury. The few extra items can be constructed on spot with some cement and a few pieces of timber.

\section{Acknowledgements}

The results quoted above were obtained on projects carried out in Philippines, Dialogos, Denmark, in Indonesia, GAHP, in Bolivia, European Union, Plagbol and Blacksmith N.Y. Gold and mercury analysis were carried out at Actlabs, Canada.

\section{References}

[1] UNEP (2013) Global Mercury Assessment 2013: Sources, Emissions, Releases and Environmental Transport. UNEP Chemicals Branch, Geneva, 271.

[2] United States Geological Survey USGS (2010) Minerals Yearbook Philippines. http://minerals.usgs.gov/minerals/pubs/country/2010/myb3-2010-rp.pdf

[3] Educational Video Demonstrating the Borax Gold Extraction Process. http://youtu.be/X6Sawj0HyF0

[4] Køster-Rasmussen, R., Westergaard, M.L., Brasholdt, M., Jørs, E. and Thomsen, J.F. (2014) Large Scale Mercury Pollution from Small-Scale gold Mining-A 2-Year Intervention Study of Implementing the Borax-Method with a Civil Society Strategy; New Solutions. Journal of Environmental and Occupational Health Policy. (In Press) 
[5] Bonde, J.B. (2013) Occupational Causes of Male Infertility. Current Opinion in Endocrinology, Diabetes and Obesity, 20, 234-239. http://dx.doi.org/10.1097/MED.0b013e32835f3d4b

[6] Duydu, Y., Başaran, N., Üstündağ, A., Aydin, S., Ündeğer, Ü., Ataman, O.Y., Aydos, K., Düker, Y., Ickstadt, K., Waltrup, B.S., Golka, K. and Bolt, H.M. (2011) Reproductive Toxicity Parameters and Biological Monitoring in Occupationally and Environmentally Boron-Exposed persons in Bandirma, Turkey. Archives of Toxicology, 85, 589-600. http://dx.doi.org/10.1007/s00204-011-0692-3

[7] Robbins, W.A., Xun, L., Jia, J., Kennedy, N., Elashoff, D.A. and Ping, L. (2010) Chronic Boron Exposure and Human Semen Parameters. Reproductive Toxicology, 29, 184-190. http://dx.doi.org/10.1016/j.reprotox.2009.11.003

[8] Scialli, A.R., Bonde, J.P., Brüske-Hohlfeld, I., Dwight Culver, B., Li, Y. and Sullivan, F.M. (2010) An Overview of Male Reproductive Studies of Boron with an Emphasis on Studies of Highly Exposed Chinese Workers. Reproductive Toxicology, 29, 10-24. http://dx.doi.org/10.1016/j.reprotox.2009.10.006 